\title{
Amyloid $\beta$ precursor protein silencing attenuates epithelial-mesenchymal transition of nasopharyngeal carcinoma cells via inhibition of the MAPK pathway
}

\author{
JIN XU ${ }^{1}$, YIN YING ${ }^{2}$, GAOYUN XIONG ${ }^{1}$, LIQIN LAI $^{3}$, QINGLIANG WANG ${ }^{1}$ and YUE YANG ${ }^{3}$ \\ Departments of ${ }^{1}$ Otolaryngology, ${ }^{2}$ Pharmacy and ${ }^{3}$ Pathology, \\ Tongde Hospital of Zhejiang Province, Hangzhou, Zhejiang 310012, P.R. China
}

Received July 23, 2018; Accepted February 28, 2019

DOI: $10.3892 / \mathrm{mmr} .2019 .10293$

\begin{abstract}
Advances in the treatment of nasopharyngeal carcinoma (NPC) have significantly improved the local control rate; however, distant metastasis remains a principal cause of mortality. Previous studies have demonstrated that the expression levels of amyloid $\beta$ precursor protein (APP) are increased in NPC. The present study aimed to investigate the association between APP and the development of NPC. In order to knockdown APP expression, an APP-small interfering RNA vector was synthesized and transfected into SUNE-1 cells. Cell Counting Kit-8 assay was performed to assess cell viability. The migratory and invasive abilities of SUNE-1 cells were examined by wound healing and Transwell assays, respectively. Reverse transcription-quantitative polymerase chain reaction and western blotting were performed to measure the mRNA and protein expression levels of APP, and additional factors involved in epithelial-mesenchymal transition (EMT) and in the mitogen-activated protein kinase (MAPK) signaling pathway. APP silencing significantly suppressed cell viability, migration and invasion. In addition, APP interference downregulated the expression levels of metastasis-associated 1, matrix metalloproteinase (MMP)-2 and MMP-9; however, knockdown of APP led to upregulation of tissue inhibitor of metalloproteinases 2 and inhibited EMT. The phosphorylation levels of p38, extracellular signalregulated kinases $1 / 2$ and c-Jun $\mathrm{N}$-terminal kinases $1 / 2$ were decreased following downregulation of APP. The present results suggested that APP knockdown may significantly inhibit the development of NPC by suppressing cell viability, migration and invasion, and by inhibiting the EMT process via
\end{abstract}

Correspondence to: Dr Yue Yang, Department of Pathology, Tongde Hospital of Zhejiang Province, 234 Gucui Road, Hangzhou, Zhejiang 310012, P.R. China

E-mail: yuey_yangyy@163.com

Key words: nasopharyngeal carcinoma, epithelial-mesenchymal transition, amyloid $\beta$ precursor protein, mitogen-activated protein kinase pathway downregulation of the MAPK signaling pathway. Therefore, APP may facilitate the development of a novel gene therapy for the treatment of NPC.

\section{Introduction}

The incidence of nasopharyngeal carcinoma (NPC) is particularly high in Southern China, and radiotherapy and chemotherapy are effective therapeutic strategies for its treatment (1). Recent advances in the treatment of NPC have led to an improvement in the local control rate; however, the distant metastasis rate of NPC remains high $(2,3)$. Notably, $>60 \%$ of unsuccessful treatments are due to distant metastasis $(4,5)$. Therefore, numerous studies have aimed to investigate the mechanism of distant metastasis, in order to improve the treatment of locally advanced NPC. Epithelial-mesenchymal transition (EMT) is one of the processes involved in distant metastasis of tumor cells, which may promote uncontrolled growth, migration and invasion of epithelial cancer cells (6-8). Various extracellular signaling molecules promote EMT, including transforming growth factor- $\beta$ (TGF- $\beta$ ), fibroblast growth factor and epidermal growth factor, via a series of cascade reactions (9-11). The mitogen-activated protein kinase (MAPK) signaling pathway is a signal transduction pathway that is able to induce transcriptional alterations downstream to the aforementioned extracellular signals (12). Additionally, hyperactivation of the MAPK signaling pathway may induce metastasis in human breast cancer (13).

Amyloid $\beta$ precursor protein (APP) is a key gene involved in Alzheimer's disease $(14,15)$. A previous study identified the upregulation of APP expression in various types of tumor cells (16). Proteomic profiling of TGF- $\beta 1$-treated NPC CNE-2 cells identified an increase in the protein expression levels of APP (17). Bioinformatics analyses demonstrated that APP is differentially expressed in NPC tissues compared with healthy tissues, and it exhibits druggable domains (18). Hérard et al (19) reported that transfection of cells with a small interfering RNA (siRNA) targeting APP significantly decreases the protein expression levels of presynaptic APP and amyloid $\beta$ precursor-like protein 2 . Additionally, siRNA targeting APP decreases glucose metabolism in neurons in the superior colliculus (19). In order to further investigate 
the mechanism underlying APP function, previous studies established an APP-siRNA plasmid vector, which laid the foundation for further studies examining the role of APP in vitro $(20,21)$. APP silencing is able to effectively suppress the proliferation, migration and invasion of tumor cells (22). However, whether APP silencing may inhibit NPC development remains unclear.

In the present study, an APP-siRNA plasmid was designed and successfully transfected into NPC cells. The expression levels of EMT-associated factors were investigated in NPC cells, and the molecular effects of APP silencing on NPC cells were investigated.

\section{Materials and methods}

Cell culture. Human NPC cell lines C666-1, 6-10B, HNE3 and SUNE-1, and the normal nasopharyngeal-derived epithelial cell line NP69, were purchased from Xiangya Medical College Cell Bank (Changsha, China). Cells were maintained in Dulbecco's modified Eagle's medium/Ham's F12 nutrient mixture (DMEM/F-12; cat. no. 11320082; Gibco; Thermo Fisher Scientific, Inc., Waltham, MA, USA) supplemented with $10 \%$ fetal bovine serum (FBS; cat. no. 10099141; Gibco; Thermo Fisher Scientific, Inc.). All cells were maintained at $37^{\circ} \mathrm{C}$ in a humidified incubator containing $5 \% \mathrm{CO}_{2}$.

Experimental grouping. Cells were randomly divided into the following three groups: i) Untransfected SUNE-1 cells (control group), ii) SUNE-1 cells transfected with empty vector (empty vector group) and SUNE-1 cells transfected with APP-siRNA vector (APP-siRNA group).

Cell transfection. The pSUPER vector (Oligoengine, Seattle, WA, USA) containing APP-siRNA (siRNA sequence: 5'-GAUCCAUCAGGGACCAAAACC-3') was purchased from Sangon Biotech Co., Ltd. (Shanghai, China). SUNE-1 cells were seeded in 6-well plates $\left(3 \times 10^{6}\right.$ cells/well) and transfected with APP-siRNA (100 nM) and empty vector $(100 \mathrm{nM})$ using Lipofectamine ${ }^{\circledR} 2000$ (Invitrogen; Thermo Fisher Scientific, Inc.), according to the manufacturer's protocol. The mixture containing APP-siRNA/empty vector, SUNE-1 cells and transfection reagents was incubated at $37^{\circ} \mathrm{C}$ for $6 \mathrm{~h}$, and then the whole mixture was transferred to DMEM/F12 medium supplemented with $10 \%$ FBS. After $48 \mathrm{~h}$, the cells were harvested and the transfection efficiency of APP-siRNA was examined.

Cell viability. Cell Counting Kit-8 (CCK-8; Beijing Solarbio Science \& Technology Co., Ltd., Beijing, China) was used to measure cell viability. Cells were seeded in 96-well plates at a density of $1 \times 10^{3}$ cells/well. The cells were cultured in a humidified incubator and were subsequently harvested at 12,24 and $48 \mathrm{~h}$. Subsequently, CCK-8 solution $(10 \mu \mathrm{l})$ was added to the culture medium and incubated at $37^{\circ} \mathrm{C}$ for $2 \mathrm{~h}$. Optical density (OD) was measured at $450 \mathrm{~nm}$ using a microplate reader (Cany Precision Instruments Co., Ltd., Shanghai, China). The blank control group comprised culture medium and CCK- 8 solution without cells. The relative cell viability was measured as follows: Cell viability $=\left(\mathrm{OD}_{\text {transfected cells }}-\mathrm{OD}_{\text {blank }}\right) /\left(\mathrm{OD}_{\text {control }}-\mathrm{OD}_{\text {blank }}\right)$.
Wound healing assay. Migration of SUNE-1 cells was quantified using a wound healing assay. Cells $\left(1 \times 10^{6}\right.$ cells/well) were seeded in 6-well plates with complete medium. The cells were starved in serum-free complete medium for $6-8 \mathrm{~h}$, and a 200- $\mu 1$ pipette tip was used to create a straight wound in the cell monolayers. Cell migration was assessed by measuring the relative size of the wounds at 12 and $24 \mathrm{~h}$ compared with at $0 \mathrm{~h}$ post-wounding using a light microscope (Nikon Corporation, Tokyo, Japan).

Transwell assay. Transwell chambers were used to assess cell invasion. Briefly, $1 \times 10^{5}$ cells were resuspended in serum-free medium and plated into the upper chamber containing polycarbonate membranes (pore size, $8 \mu \mathrm{m}$; Corning Inc., Corning, NY, USA) coated with Matrigel ${ }^{\circledR}$ (BD Biosciences, San Jose, CA, USA). DMEM/F12 containing 10\% FBS was added to the lower chamber and cells were incubated at $37^{\circ} \mathrm{C}$ for $24 \mathrm{~h}$. Cells remaining on the surface of the upper chamber were removed with a cotton swab. The invading cells were fixed with $4 \%$ paraformaldehyde for $15 \mathrm{~min}$ at room temperature, and stained with $0.1 \%$ crystal violet solution for $20 \mathrm{~min}$ at room temperature. To assess cell invasion, three randomly selected fields of view were observed under a light microscope (magnification, $\mathrm{x} 200$ ). The invasion rate was calculated by counting the number of invading cells at 0 and $24 \mathrm{~h}$.

Reverse transcription-quantitative polymerase chain reaction $(R T-q P C R)$. Total RNA was extracted from SUNE-1 cells $\left(2 \times 10^{4}\right.$ cells/well in 6-well plates) using TRIzol ${ }^{\circledR}$ (Invitrogen; Thermo Fisher Scientific, Inc.), according to the manufacturer's protocol. Extracted RNA was treated with RNase-free DNase (Takara Biotechnology Co., Ltd., Dalian, China). Prime Script first strand cDNA synthesis kit (Takara Biotechnology Co., Ltd.) was used to reverse transcribe the RNA to cDNA, as previously described (23). Briefly, total RNA ( $2 \mu \mathrm{g})$ was used as template, and the RT reaction was performed at $65^{\circ} \mathrm{C}$ for $5 \mathrm{~min}$, followed by incubation at $30^{\circ} \mathrm{C}$ for $6 \mathrm{~min}$ and $50^{\circ} \mathrm{C}$ for $60 \mathrm{~min}$. Primer sequences are listed in Table I. The ABI 7500 Fast Real-Time PCR system (Applied Biosystems; Thermo Fisher Scientific, Inc.) was used for examining the expression levels of EMT- and MAPK-associated genes in SUNE-1 cells using a SYBR Green master mix (Fermentas; Thermo Fisher Scientific, Inc.). The RT-qPCR reaction mixture (20 $\mu \mathrm{l})$ contained $1 \mu \mathrm{l}$ forward and $1 \mu \mathrm{l}$ reverse primers (concentration, $10 \mu \mathrm{M}$ ), $10 \mu 1$ SYBR Green master mix, $2 \mu \mathrm{l}$ cDNA and RNase-free $\mathrm{dH}_{2} \mathrm{O}$. RT-qPCR was performed using the following thermocycling conditions: Initial denaturation at $94^{\circ} \mathrm{C}$ for $3 \mathrm{~min}$, followed by 40 cycles at $94^{\circ} \mathrm{C}$ for $30 \mathrm{sec}, 56^{\circ} \mathrm{C}$ for $30 \mathrm{sec}$ and $72^{\circ} \mathrm{C}$ for $2 \mathrm{~min}$, with a final extension at $72^{\circ} \mathrm{C}$ for $10 \mathrm{~min}$. GAPDH was used as the internal control. The relative mRNA expression levels were calculated using the $2^{-\Delta \Delta \mathrm{Cq}}$ method (24).

Western blotting. Total protein was extracted from SUNE-1 cells $\left(2 \times 10^{4}\right.$ cells/well in 6-well plates) using RIPA buffer (Beijing Solarbio Science \& Technology Co., Ltd.), and the protein concentration was determined using a bicinchoninic acid protein assay kit (Takara Biotechnology Co., Ltd.). Proteins $(30 \mu \mathrm{g} / \mathrm{lane})$ were separated by $10 \%$ SDS-PAGE and transferred to polyvinylidene fluoride (PVDF) membranes 
Table I.Primer sequences for reverse transcription-quantitative polymerase chain reaction.

\begin{tabular}{ll}
\hline Gene symbol & \multicolumn{1}{c}{ Primer sequence } \\
\hline APP & F: 5'-TGGCCCTGGAGAACTACATC-3' \\
& R: 5'-AATCACACGGAGGTGTGTCA-3' \\
MTA-1 & F: 5'-AGCTACGAGCAGCACAACGGGGT-3' \\
& R: 5'-CACGCTTGGTTTCCGAGGAT-3' \\
TIMP-2 & F: 5'-CCAAAGCAGTGAGCGAGAA-3' \\
& R: 5'-CATCCAGAGGCACTCATCC-3 \\
MMP-2 & F: 5'-GGAGGCACGATTGGTCTG-3' \\
& R: 5'-TTGGTTTCCGCATGGTCT-3 \\
MMP-9 & F: 5'-TTGACAGCGACAAGAAGTGG-3' \\
& R: 5'-GGCACAGTAGTGGCCGTAG-3 \\
GAPDH & F: 5'-ACCACAGTCCATGAAATCAC-3' \\
& R: 5'-AGGTTTCTCCAGGCGGCATG-3 \\
\hline
\end{tabular}

APP, amyloid $\beta$ precursor protein; F, forward; MMP, matrix metalloproteinase; MTA-1, metastasis-associated 1; R, reverse; TIMP-2, tissue inhibitor of metalloproteinases 2 .

(Thermo Fisher Scientific, Inc.). Subsequently, the PVDF membranes were placed in blocking buffer (1X TBS with $0.1 \%$ Tween-20 and 5\% non-fat dry milk) for $1 \mathrm{~h}$ at room temperature. All primary antibodies were diluted to 1:1,000 with blocking buffer, and the membranes were incubated with these primary antibodies at $4^{\circ} \mathrm{C}$ overnight. All primary and secondary antibodies were purchased from Cell Signaling Technology, Inc. (Danvers, MA, USA). The primary antibodies used were as follows: Anti-GAPDH (cat. no. 5174), anti-APP (cat. no. 2452), anti-metastasis-associated 1 (MTA-1; cat. no. 5646), anti-tissue inhibitor of metalloproteinases 2 (TIMP-2; cat. no. 5738), anti-matrix metalloproteinase (MMP)-2 (cat. no. 4022), anti-MMP-9 (cat. no. 3852), anti-phosphorylated (p)-p38 (cat. no. 9211), anti-p38 (cat. no. 9212), anti-p-extracellular signal-regulated kinases $1 / 2$ (ERK1/2; cat. no. 9102), anti-ERK1/2 (cat. no. 9101), anti-p-c-Jun N-terminal kinases 1/2 (JNK; cat. no. 9251) and anti-JNK (cat. no. 9252). Following incubation with primary antibodies, the PVDF membranes were incubated with the appropriate secondary antibody for $2 \mathrm{~h}$ at room temperature. The secondary antibodies used were as follows: Anti-rabbit immunoglobulin $\mathrm{G}$ (IgG) horseradish peroxidase (HRP)-conjugated antibody (cat. no. 7074; 1:2,000). The signals were detected using Pierce ECL Western Blotting Substrate (cat. no. 32106; Pierce; Thermo Fisher Scientific, Inc.). Optical band density was semi-quantified using ImageJ software (version 1.46; National Institutes of Health, Bethesda, MD, USA). GAPDH was used as the internal control.

Statistical analysis. Data are presented as the means \pm standard error of the mean. GraphPad Prism 6.0 (GraphPad Software, Inc., La Jolla, CA, USA) was used to perform statistical analysis. Data were analyzed using one-way analysis of variance followed by Tukey's post hoc test. $\mathrm{P}<0.05$ was considered to indicate a statistically significant difference.

\section{Results}

APP-siRNA inhibits viability of SUNE-1 cells. The expression levels of APP were significantly increased in NPC cells compared with in NP69 cells (Fig. 1A and B). The mRNA expression levels of APP were highest in SUNE-1 cells among all of the NPC cell lines tested; therefore, SUNE-1 cells were selected for further experiments. Post-transfection with APP-siRNA, the mRNA and protein expression levels of APP were assessed by RT-qPCR and western blotting, respectively (Fig. 1C and D). The results revealed that the expression levels of APP were efficiently decreased following APP-siRNA transfection compared with in the control groups. Cell viability was assessed using the CCK- 8 assay, and the results suggested that APP-siRNA significantly inhibited cell viability at $48 \mathrm{~h}$; in addition, a slight effect was observed at $24 \mathrm{~h}$ (Fig. 1E).

APP-siRNA suppresses migration and invasion of SUNE-1 cells. Wound healing and Transwell assays were used to investigate the effects of APP-siRNA on migration and invasion of SUNE-1 cells, respectively. The present data suggested that APP-siRNA was able to decrease the migratory and invasive abilities of SUNE-1 cells compared with in the control groups (Fig. 2A and B). Collectively, the present results indicated that APP may be involved in migration and invasion of SUNE-1 cells.

APP-siRNA suppresses EMT in SUNE-1 cells. EMT serves an important role in the invasion and metastasis of tumor cells (25). To investigate the effects of APP-siRNA on EMT in SUNE-1 cells, the expression levels of MTA-1, TIMP-2, MMP-2 and -9 were assessed using RT-qPCR (Fig. 3A-D) and western blotting (Fig. 3E). Compared with the control groups, APP knockdown led to a significant decrease in the expression levels of MTA-1, MMP-2 and -9; however, APP silencing increased the mRNA and protein expression levels of TIMP-2. The present results suggested that APP-siRNA may inhibit EMT by regulating the expression levels of associated factors.

APP-siRNA suppresses activation of the MAPK signaling pathway. The present study investigated the effects of APP-siRNA on MAPK pathway. The protein expression levels of ERK1/2, p38 and JNK1/2, and their corresponding phosphorylated forms, were measured by western blotting (Fig. 4A). The present results suggested that, compared with the control groups, APP silencing did not affect the protein expression levels of total ERK1/2, p38 and JNK1/2; however, it did significantly decrease their phosphorylation levels (Fig. 4B-D). Collectively, the present results suggested that APP-siRNA was able to decrease the phosphorylation of MAPK signaling factors.

\section{Discussion}

Previous studies have demonstrated that APP is a membranebound protein present in multiple cell types; notably, the expression levels of APP are increased in various types of cancer cells $(16,26)$. A previous study reported that the proliferation, migration and invasion of CNE-2 cells treated with anti-APP antibody are significantly decreased compared 
A
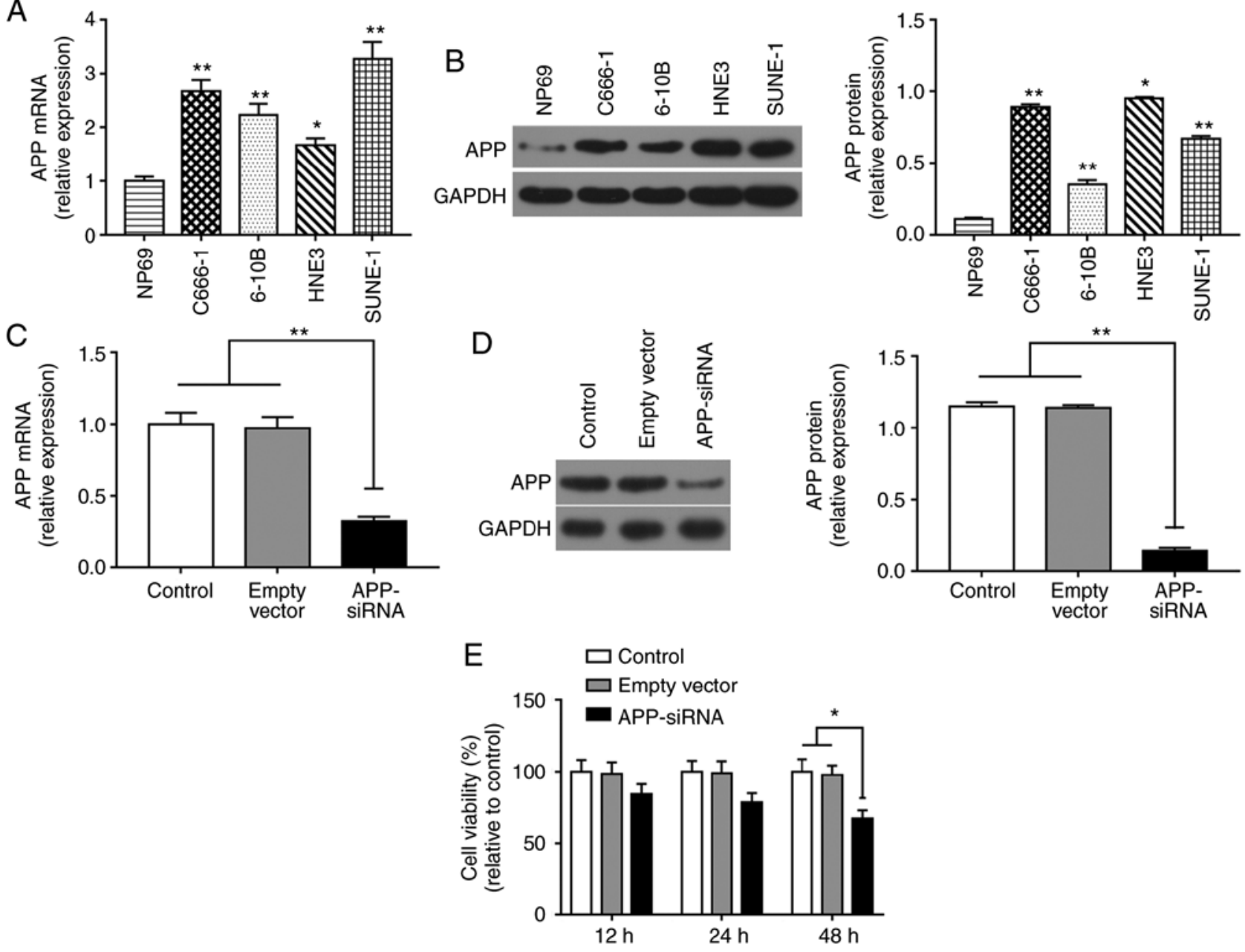

Figure 1. APP-siRNA inhibits the viability of SUNE-1 cells. (A) mRNA expression levels of APP in the four NPC cell lines C666-1, 6-10B, HNE-3 and SUNE-1, and in the normal nasopharyngeal-derived epithelial cell line NP69, as assessed by RT-qPCR. (B) Protein expression levels of APP in NP69, C666-1, 6-10B, HNE-3 and SUNE-1 cells, as assessed by western blotting. ${ }^{*}<0.05,{ }^{* *} \mathrm{P}<0.01$ vs. NP69 cells. (C) mRNA expression levels of APP following APP knockdown, as assessed by RT-qPCR. (D) Protein expression levels of APP following APP knockdown, as assessed by western blotting. (E) Cell Counting Kit-8 analysis was performed to investigate cell viability following APP knockdown at 12,24 and $48 \mathrm{~h}$. ${ }^{*} \mathrm{P}<0.05,{ }^{* *} \mathrm{P}<0.01$. GAPDH was used as the internal control for western blotting. Data are presented as the means \pm standard error of the mean $(n=3)$. APP, amyloid $\beta$ precursor protein; RT-qPCR, reverse transcription-quantitative polymerase chain reaction; siRNA, small interfering RNA.

with in a control group (27). In addition, a previous study compared 10 control and 31 NPC cell lines, and observed that APP is differentially expressed in NPC cells, thus suggesting an association between APP and the occurrence and development of NPC (18). In the present study, the mRNA and protein expression levels of APP were significantly upregulated in NPC cells. The discrepancy between mRNA and protein expression levels in various cell lines may be due to the post-transcriptional regulation of APP, which remains unclear (28). In the present study, the protein and mRNA expression levels of APP were increased in SUNE-1 cells compared with in normal NP69 cells. Therefore, SUNE-1 cells were selected for further experiments. In the present study, the effects of APP-siRNA on cell viability, migration and invasion were investigated. APP knockdown was able to significantly inhibit the viability, migration and invasion of SUNE-1 cells. Furthermore, knockdown of APP increased the expression levels of TIMP-2; however, APP-siRNA decreased the mRNA expression levels of MTA-1, MMP-2 and -9. Additionally, APP knockdown significantly decreased the phosphorylation levels of MAPK-associated factors. Collectively, the present data suggested that APP-siRNA may suppress the occurrence, development and metastasis of human NPC.

EMT is a necessary process underlying distant metastasis of tumor cells (29). The present findings suggested an association between APP and EMT in SUNE-1 cells. In the present study, the protein expression levels of factors involved in EMT were decreased in the APP-siRNA group compared with in the control group. The EMT process involves various proteins. $\beta$-catenin interacts with E-cadherin to form complexes that promote intercellular adhesion. $\beta$-catenin is able to enter the nucleus and to induce the expression of T-cell-factor/lymphoid enhancer binding factor 1 , thus increasing the protein expression levels of vimentin and MMPs, promoting EMT $(30,31)$. Previous studies have demonstrated that TIMP-2 inhibits the activity of MMP-2 and -9, thus decreasing degradation of the extracellular matrix (ECM), and inhibiting tumor invasion and metastasis $(32,33)$. In addition, MTA-1 has been identified to be associated with tumorigenesis, tumor invasion and metastasis (34-36). The present results suggested that APP-siRNA 

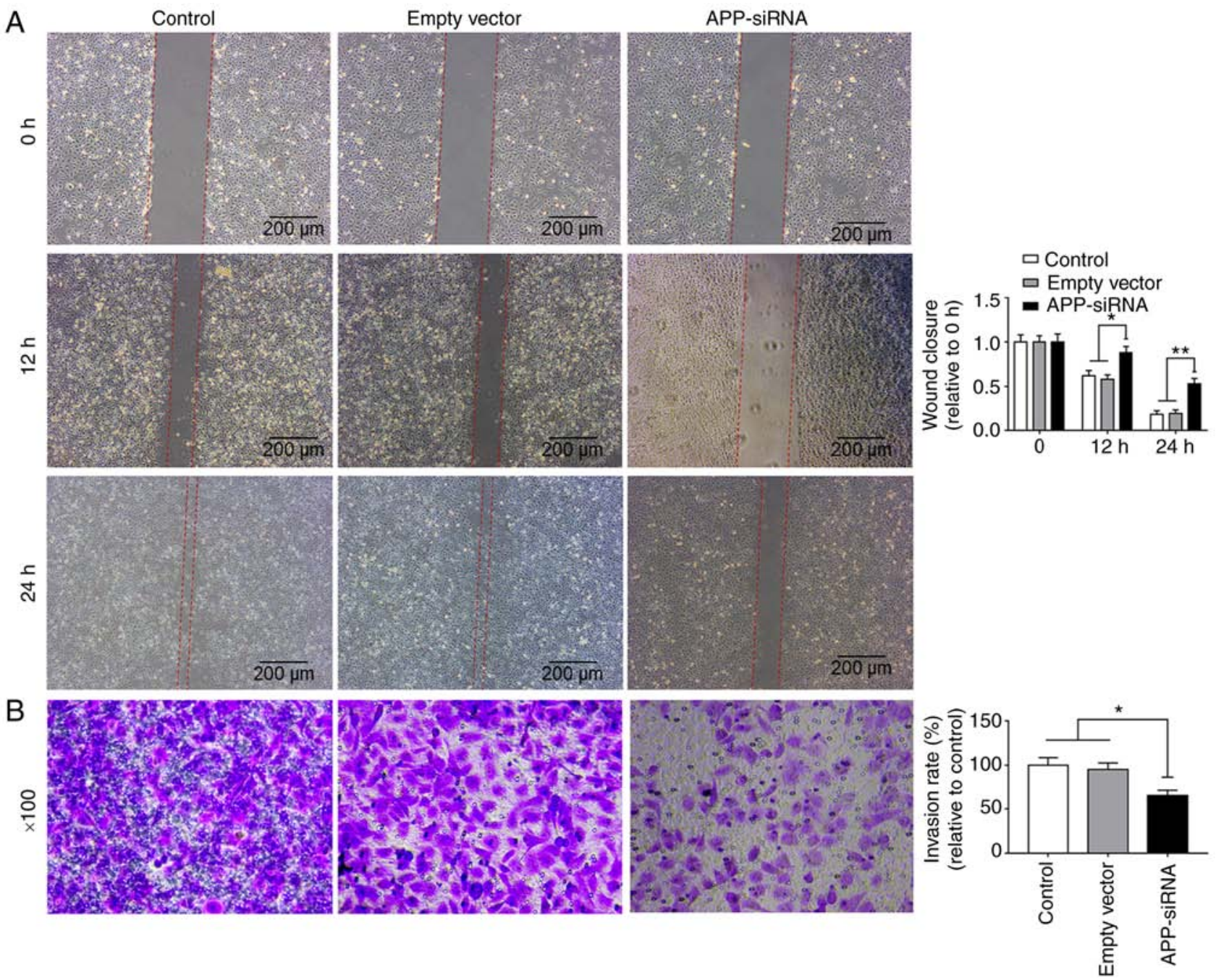

Figure 2. APP-siRNA suppresses the migration and invasion of SUNE-1 cells. (A) Cell migration in control, empty vector and APP-siRNA groups at 0,12 and $24 \mathrm{~h}$ following wounding. (B) Effects of APP silencing on cell invasion was measured using Transwell assay. Data are presented as the means \pm standard error of the mean $(\mathrm{n}=3) .{ }^{*} \mathrm{P}<0.05,{ }^{* *} \mathrm{P}<0.01$. APP, amyloid $\beta$ precursor protein; siRNA, small interfering RNA.
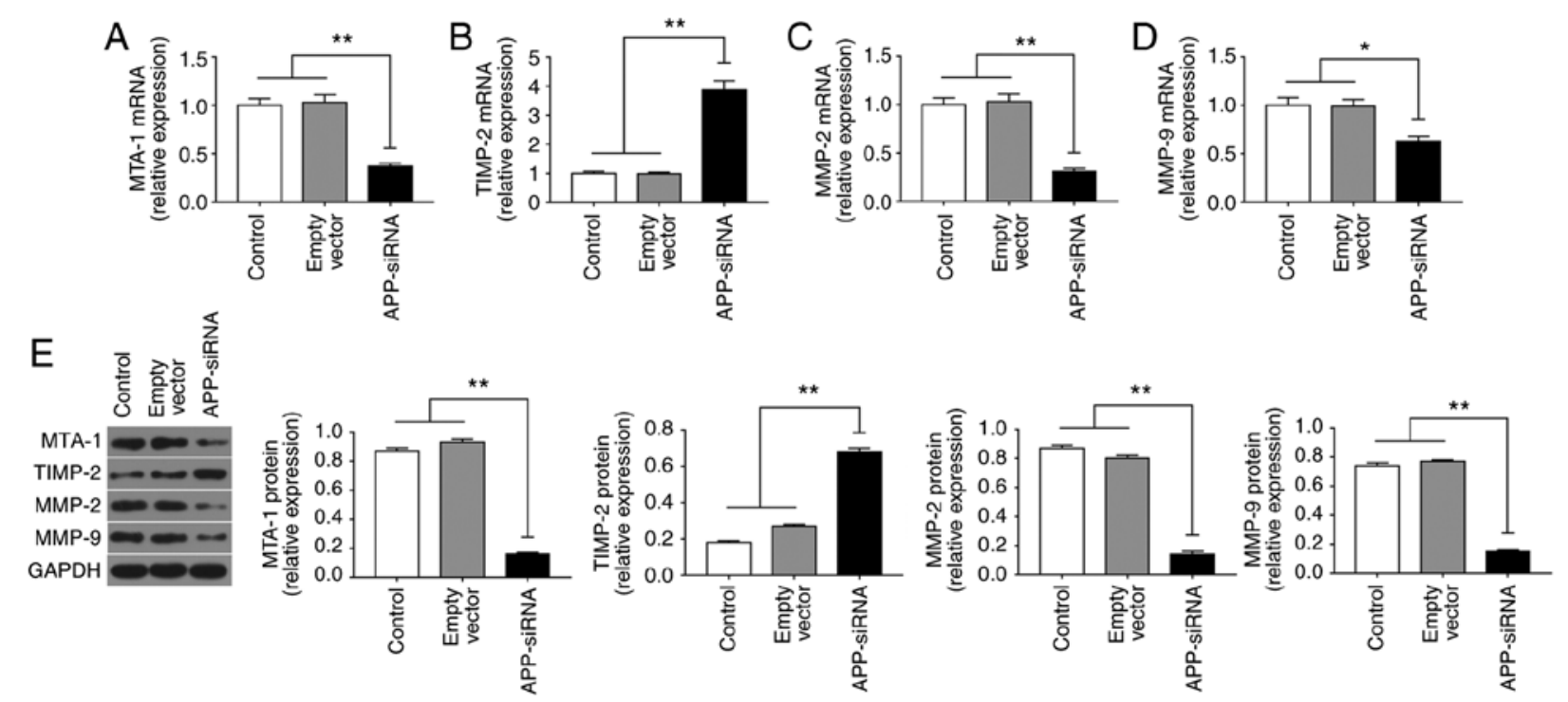

Figure 3. APP-siRNA suppresses the expression of MTA-1 and EMT-associated markers in SUNE-1 cells. mRNA expression levels of (A) MTA-1, (B) TIMP-2, (C) MMP-2 and (D) MMP-9 were assessed using reverse transcription-quantitative polymerase chain reaction. (E) Protein expression levels of EMT-associated factors were assessed using western blotting in control, empty vector and APP-siRNA groups. GAPDH was used as the internal control for western blotting. Data are presented as the means \pm standard error of the mean $(n=3) .{ }^{*} \mathrm{P}<0.05,{ }^{* *} \mathrm{P}<0.01$. APP, amyloid $\beta$ precursor protein; EMT, epithelial-mesenchymal transition; MMP, matrix metalloproteinase; MTA-1, metastasis-associated 1; siRNA, small interfering RNA; TIMP-2, tissue inhibitor of metalloproteinases 2. 

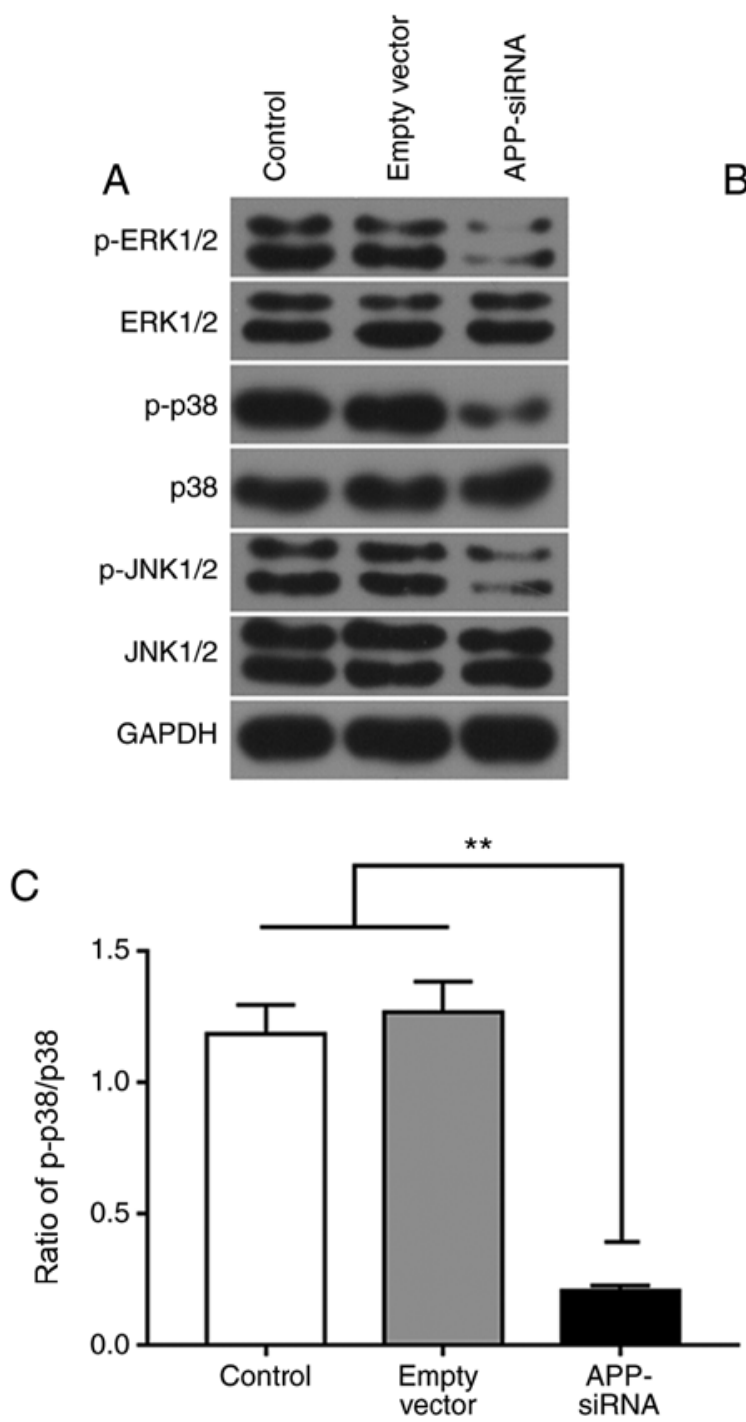
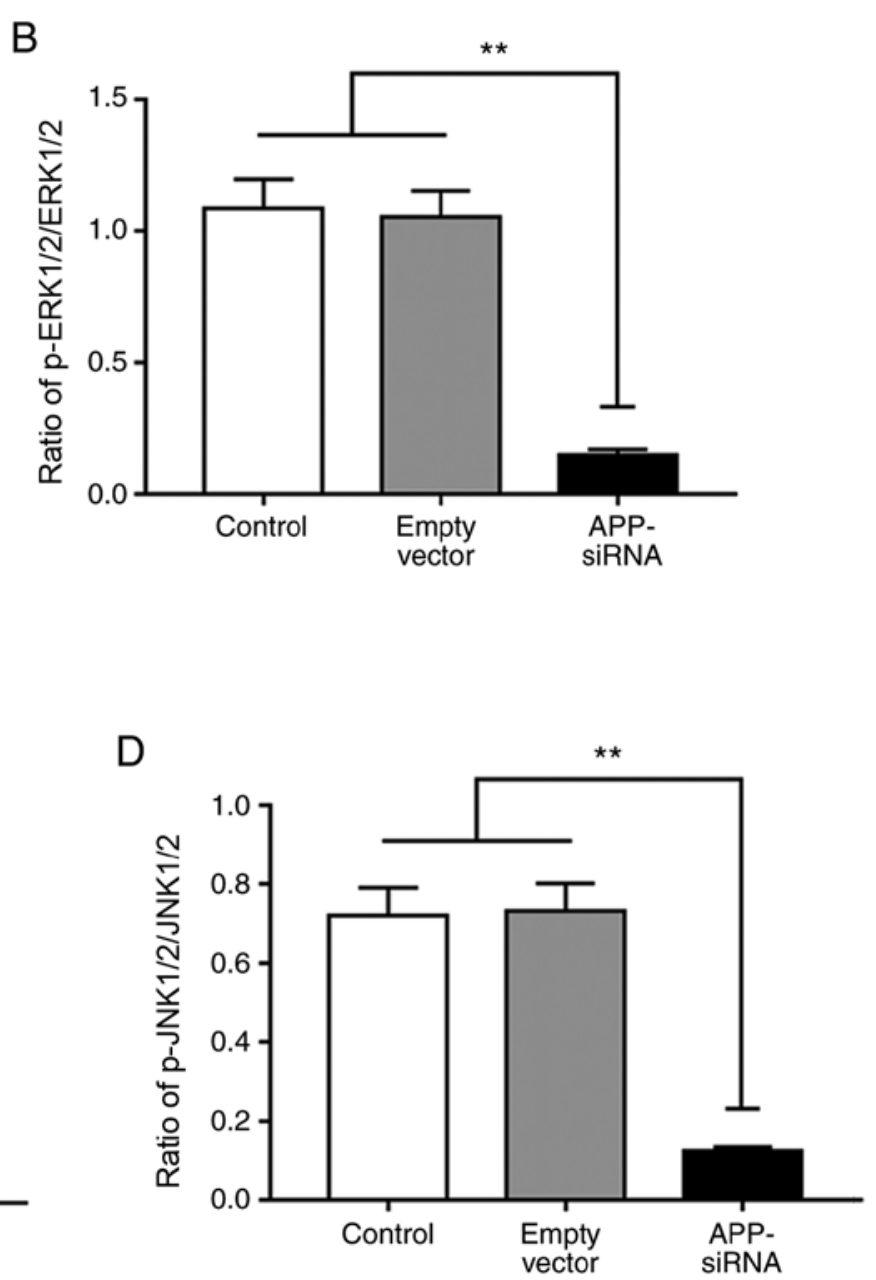

Figure 4. APP-siRNA suppresses the activation of the MAPK signaling pathway. Protein expression levels of (A) ERK1/2, p38 and JNK1/2, and their corresponding phosphorylated forms, were detected by western blotting in SUNE-1 cells. The ratio of (B) p-ERK1/2/ERK1/2,(C) p-p38/p38 and (D) p-JNK1/2/JNK1/2 protein expression levels. GAPDH was used as the internal control for western blotting. Data are presented as the means \pm standard error of the mean ( $=3$ ). ${ }^{* *} \mathrm{P}<0.01$. APP, amyloid $\beta$ precursor protein; ERK, extracellular signal-regulated kinases; JNK, c-Jun N-terminal kinases; MAPK, mitogen-activated protein kinase; p-, phosphorylated; siRNA, small interfering RNA.

was able to increase the expression level of TIMP-2, and to decrease the expression levels of MMP-2 and -9. These findings suggested that the balance between TIMP-2 and MMPs may be gradually restored, which may facilitate recovery of the dynamic equilibrium in ECM and decrease migration and invasion of SUNE-1 cells. In addition, the expression levels of MTA-1 were decreased following APP-siRNA transfection, indicating that APP-siRNA inhibited the metastasis of SUNE-1 cells by downregulating the expression of MTA-1.

The present results suggested that APP-siRNA was able to simultaneously suppress multiple factors involved in EMT, thus regulating tumor cell migration and invasion. Additionally, the mechanism underlying this effect may involve an upstream signaling pathway. A previous study observed that overexpression of aurora kinase A promotes hyperactivation of the MAPK signaling pathway, thus inducing EMT and invasion of NPC cells (37). The present results suggested that APP exhibited a similar effect, and may increase EMT and the activity of the MAPK signaling pathway. Previous studies have demonstrated that activation of p38 and JNK is involved in EMT in response to advanced glycation end products. Additionally, EMT may be induced by activated ERK signaling in renal tubular cell lines and mouse mammary gland epithelial cells in vitro (38-40). The present results suggested that APP knockdown decreased the protein expression levels of p-ERK1/2, p-p38 and p-JNK1/2, thus decreasing the activity of the MAPK signaling pathway. A large number of studies have demonstrated that p-ERK1/2 (41-43), p-JNK (44-46) and p-p38 $(40,47,48)$ serve an important role in regulating EMT. Taken together, downregulation of the protein expression levels of p-ERK1/2, p-p38 and p-JNK1/2 in the APP-siRNA group suggested that APP silencing may inhibit the EMT process by suppressing the MAPK signaling pathway in SUNE-1 cells. However, the present study was performed using only one cell line, and further studies are required to confirm the role of APP in multiple NPC cells and in vivo.

In conclusion, the present results suggested that APP knockdown decreased the viability, migration and invasion of 
SUNE-1 cells. APP silencing increased the expression levels of TIMP-2; however, it decreased the expression levels of MTA-1, MMP-2 and -9, thus suggesting that EMT was inhibited in SUNE-1 cells. Notably, APP silencing may suppress cell migration, invasion and EMT by inhibiting the MAPK signaling pathway. Therefore, APP may be considered a novel biomarker for NPC surveillance, and as a therapeutic target to treat patients with NPC. The present findings may improve the understanding of NPC and may facilitate the development of a novel gene therapy for the treatment of NPC.

\section{Acknowledgements}

Not applicable.

\section{Funding}

No funding was received.

\section{Availability of data and materials}

The datasets used and/or analyzed during the present study are available from the corresponding author on reasonable request.

\section{Authors' contributions}

JX made substantial contributions to the conception and design of the study. YYi, GX, LL, QW and YYa were involved in data acquisition, analysis and interpretation. All authors were involved in drafting or critically revising the manuscript, and approved of the final version to be published. All authors agreed to be accountable for all aspects of the work in ensuring that questions related to the accuracy or integrity of the work are appropriately investigated and resolved.

\section{Ethics approval and consent to participate}

Not applicable.

\section{Patient consent for publication}

Not applicable.

\section{Competing interests}

The authors declare that they have no competing interests.

\section{References}

1. Teo PM, Kwan WH, Lee WY, Leung SF and Johnson PJ: Prognosticators determining survival subsequent to distant metastasis from nasopharyngeal carcinoma. Cancer 77: 2423-2431, 1996

2. Wan G, Peng XU and Lang J: Research progress of neoadjuvant chemotherapy for locally advanced nasopharyngeal carcinoma. Cancer Res Prev Treat 43: 2016 (In Chinese).

3. Zheng LS, Yang JP, Cao Y, Peng LX, Sun R, Xie P, Wang MY, Meng DF, Luo DH, Zou X, et al: SPINK6 promotes metastasis of nasopharyngeal carcinoma via binding and activation of epithelial growth factor receptor. Cancer Res 77: 579-589, 2017.

4. Liu X, Lu J, He ML, Li Z, Zhang B, Zhou LH, Li Q, Li G, Wang L, Tian WD, et al: Antitumor effects of interferon-alpha on cell growth and metastasis in human nasopharyngeal carcinoma. Current Cancer Drug Targets 12: 561-570, 2012.
5. Lee CC, Huang TT, Lee MS, Hsiao SH, Lin HY, Su YC, Hsu FC and Hung SK: Clinical application of tumor volume in advanced nasopharyngeal carcinoma to predict outcome. Radiat Oncol 5: $1-6,2010$.

6. Burns WC and Thomas MC: The molecular mediators of type 2 epithelial to mesenchymal transition (EMT) and their role in renal pathophysiology. Expert Rev Mol Med 12: e17, 2010.

7. Chakrabarti R, Hwang J, Andres Blanco M, Wei Y, Lukačišin M, Romano RA, Smalley K, Liu S, Yang Q, Ibrahim T, et al: Elf5 inhibits the epithelial-mesenchymal transition in mammary gland development and breast cancer metastasis by transcriptionally repressing Snail2. Nat Cell Biol 14: 1212-1222, 2012.

8. Tsai JH, Donaher JL, Murphy DA, Chau S and Yang J: Spatiotemporal regulation of epithelial-mesenchymal transition is essential for squamous cell carcinoma metastasis. Cancer Cell 22: 725-736, 2012.

9. Li Y and Chen X: miR-4792 inhibits epithelial-mesenchymal transition and invasion in nasopharyngeal carcinoma by targeting FOXC1. Biochem Biophys Res Commun 468: 863-869, 2015.

10. Gonzalez DM and Medici D: Signaling mechanisms of the epithelial-mesenchymal transition. Sci Signal 7: re8, 2014.

11. Mccormack N and O'Dea S: Regulation of epithelial to mesenchymal transition by bone morphogenetic proteins. Cell Signal 25: 2856-2862, 2013.

12. Sun Y, Liu WZ, Liu T, Feng X, Yang N and Zhou HF: Signaling pathway of MAPK/ERK in cell proliferation, differentiation, migration, senescence and apoptosis. J Recept Signal Transduct Res 35: 600-604, 2015.

13. Klauzinska M, Castro NP, Rangel MC, Spike BT, Gray PC, Bertolette D, Cuttitta F and Salomon D: The multifaceted role of the embryonic gene Cripto-1 in cancer, stem cells and epithelial-mesenchymal transition. Semin Cancer Biol 29: 51-58, 2014.

14. Kubota T, Maruyama S, Abe D, Tomita T, Morozumi T, Nakasone N, Saku T and Yoshie H: Amyloid beta (A4) precursor protein expression in human periodontitis-affected gingival tissues. Arch Oral Biol 59: 586-594, 2014.

15. Muratore CR, Rice HC, Srikanth P, Callahan DG, Shin T, Benjamin LN, Walsh DM, Selkoe DJ and Young-Pearse TL: The familial Alzheimer's disease APPV717I mutation alters APP processing and Tau expression in iPSC-derived neurons. Hum Mol Genet 23: 3523-3536, 2014.

16. Ko SY, Lin SC, Chang KW, Wong YK, Liu CJ, Chi CW and Liu TY: Increased expression of amyloid precursor protein in oral squamous cell carcinoma. Int J Cancer 111: 727-732, 2004.

17. Liang K, Chen ZC, Yi H, Li JL, Zhang P, Li MY, Li C, Feng XP, Peng F and Xiao ZQ: Screening of EGFR-regulated secreted proteins in human NPC cell line CNE2. Prog Biochem Biophys 34: 100-106, 2007.

18. Lai CJ and Tay BH: Pharmacophore-based screening targeted at upregulated FN1, MMP-9, APP reveals therapeutic compounds for nasopharyngeal carcinoma. Comput Biol Med 69: 158-165, 2016.

19. Hérard AS, Besret L, Dubois A, Dauguet J, Delzescaux T, Hantraye P, Bonvento G and Moya KL: siRNA targeted against amyloid precursor protein impairs synaptic activity in vivo. Neurobiol Aging 27: 1740-1750, 2006.

20. Miller VM, Gouvion CM, Davidson BL and Paulson HL: Targeting Alzheimer's disease genes with RNA interference: An efficient strategy for silencing mutant alleles. Nucleic Acids Res 32: 661, 2004.

21. Shyam R, Ren Y, Lee J, Braunstein KE, Mao HQ and Wong PC: Intraventricular delivery of siRNA nanoparticles to the central nervous system. Mol Ther Nucleic Acids 4: e242, 2015.

22. Zhao YJ, Han HZ, Liang Y, Shi CZ, Zhu QC and Yang J: Alternative splicing of VEGFA,APP and NUMB genes in colorectal cancer. World J Gastroenterol 21: 6550-6560, 2015.

23. Huang Y, An L, Hui KM, Ren Q and Wang W: An LDLa domain-containing C-type lectin is involved in the innate immunity of Eriocheir sinensis. Dev Comp Immunol 42: 333-344, 2014.

24. Livak KJ and Schmittgen TD: Analysis of relative gene expression data using real-time quantitative PCR and the 2(-Delta Delta C(T)) method. Methods 25: 402-408, 2001.

25. Hugo H, Ackland ML, Blick T, Lawrence MG, Clements JA, Williams ED and Thompson EW: Epithelial-mesenchymal and mesenchymal-epithelial transitions in carcinoma progression. J Cell Physiol 213: 374-383, 2007.

26. Meng J, Kataoka H, Itoh $\mathrm{H}$ and Koono M: Amyloid beta protein precursor is involved in the growth of human colon carcinoma cell in vitro and in vivo. Int J Cancer 92: 31-39, 2015. 
27. Tang CE, Guan YJ, Yi B, Li XH, Liang K, Zou HY, Yi H, Li MY, Zhang PF, Li C, et al: Identification of the amyloid $\beta$-protein precursor and cystatin $\mathrm{C}$ as novel epidermal growth factor receptor regulated secretory proteins in nasopharyngeal carcinoma by proteomics. J Proteome Res 9: 6101-6111, 2010.

28. Wang C, Chen K, Liao S, Gu W, Lian X, Zhang J, Gao X, Liu X, Wang T, He QY, et al: The flightless I protein interacts with RNA-binding proteins and is involved in the genome-wide mRNA post-transcriptional regulation in lung carcinoma cells. Int J Oncol 51: 347-361, 2017.

29. Kraljevic Pavelic S, Sedic M, Bosnjak H, Spaventi S and Pavelic K: Metastasis: New perspectives on an old problem. Mol Cancer 10: 22, 2011

30. Shi Q, Song X, Wang J, Gu J, Zhang W, Hu J, Zhou X and Yu R FRK inhibits migration and invasion of human glioma cells by promoting $\mathrm{N}$-cadherin/ $\beta$-catenin complex formation. J Mol Neurosci 55: 32-41, 2015.

31. Li H, Wang Z, Zhang W, Qian K, Liao G, Xu W and Zhang S: VGLL4 inhibits EMT in part through suppressing Wnt/3-catenin signaling pathway in gastric cancer. Med Oncol 32: 83, 2015.

32. Eiró N, Fernandezgarcia B, Vázquez J, Casar JMD, González LO and Vizoso FJ: A phenotype from tumor stroma based on the expression of metalloproteases and their inhibitors, associated with prognosis in breast cancer. Oncoimmunology 4: e992222, 2015.

33. Salimi Sartakhti J, Manshaei MH and Sadeghi M: MMP-TIMP interactions in cancer invasion: An evolutionary game-theoretical framework. J Theor Biol 412: 17-26, 2017.

34. Zhu X, Guo Y, Li X, Ding Y and Chen L: Metastasis-associated protein 1 nuclear expression is associated with tumor progression and clinical outcome in patients with non-small cell lung cancer. J Thorac Oncol 5: 1159-1166, 2010.

35. Higashijima J, Kurita N, Miyatani T, Yoshikawa K, Morimoto S, Nishioka M, Iwata T and Shimada M: Expression of histone deacetylase 1 and metastasis-associated protein 1 as prognostic factors in colon cancer. Oncol Rep 26: 343-348, 2011.

36. Prisco MG, Zannoni GF, De Stefano I, Vellone VG, Tortorella L, Fagotti A, Mereu L, Scambia G and Gallo D: Prognostic role of metastasis tumor antigen 1 in patients with ovarian cancer: A clinical study. Hum Pathol 43: 282-288, 2012.

37. Wan XB, Long ZJ, Yan M, Xu J, Xia LP, Liu L, Zhao Y, Huang XF, Wang XR, Zhu XF, et al: Inhibition of Aurora-A suppresses epithelial-mesenchymal transition and invasion by downregulating MAPK in nasopharyngeal carcinoma cells. Carcinogenesis 29: 1930-1937, 2008.

38. Wang J, Wu Z, Pandey V, Chen Y, Zhu T and Lobie P: GP1-2: Autocrine human growth hormone suppression of E-CADHERIN via p44/42 MAPK promotes epithelial-tomesenchymal transition (EMT) of colorectal carcinoma cells. Eur J Cancer 50 (Suppl): S29, 2014.
39. Li NY, Weber CE, Wai PY, Cuevas BD, Zhang J, Kuo PC and Mi Z: An MAPK-dependent pathway induces epithelial-mesenchymal transition via Twist activation in human breast cancer cell lines. Surgery 179: 256-257, 2013.

40. Lin Y, Mallen-St CJ, Wang G, Luo J, Palma-Diaz F, Lai C, Elashoff DA, Sharma S, Dubinett SM and St John M: p38 MAPK mediates epithelial-mesenchymal transition by regulating p38IP and Snail in head and neck squamous cell carcinoma. Oral Oncol 60: 81-89, 2016.

41. Lin ZH, Wang L, Zhang JB, Liu Y, Li XQ, Guo L, Zhang B, Zhu WW and Ye QH: MST4 promotes hepatocellular carcinoma epithelial-mesenchymal transition and metastasis via activation of the p-ERK pathway. Int J Oncol 45: 629-640, 2014

42. Yu H, Zhang L and Liu P: CXCR7 signaling induced epithelial-mesenchymal transition by AKT and ERK pathways in epithelial ovarian carcinomas. Tumour Biol 36: 1679-1683, 2015.

43. Shi P, Fang C and Pang X: Astrocyte elevated gene-1 regulates CCL3/CCR5-induced epithelial-to-mesenchymal transition via Erk1/2 and Akt signaling in cardiac myxoma. Oncol Rep 34: 1319-1326, 2015.

44. Zhang Q, Li X, Li X, Li X and Chen Z: LncRNA H19 promotes epithelial-mesenchymal transition (EMT) by targeting miR-484 in human lung cancer cells. J Cell Biochem 119: 4447-4457, 2018.

45. Li H, Li Y, Liu D and Liu J: LPS promotes epithelial-mesenchymal transition and activation of TLR4/JNK signaling. Tumour Biol 35: 10429-10435, 2014.

46. Epstein Shochet G, Tartakover-Matalon S, Drucker L, Pasmanik-Chor M, Pomeranz M, Fishman A and Lishner M: Placenta-breast cancer cell interactions promote cancer cell epithelial mesenchymal transition via TGFbeta/JNK pathway. Clin Exp Metastasis 31: 961-975, 2014.

47. Takahashi E, Haga A and Tanihara H: Merlin regulates epithelial-to-mesenchymal transition of ARPE-19 Cells via TAK1-p38MAPK-mediated activation. Invest Ophthalmol Vis Sci 56: 2449-2458, 2015.

48. Ling G, Ji Q, Ye W, Ma D and Wang Y: Epithelial-mesenchymal transition regulated by $\mathrm{p} 38 / \mathrm{MAPK}$ signaling pathways participates in vasculogenic mimicry formation in SHG44 cells transfected with TGF- $\beta$ cDNA loaded lentivirus in vitro and in vivo. Int J Oncol 49: 2387-2398, 2016.

(i) $\Theta$ This work is licensed under a Creative Commons Attribution-NonCommercial-NoDerivatives 4.0 International (CC BY-NC-ND 4.0) License. 